\title{
FUNCIONAMIENTO DEL SISTEMA POLÍTICO Y ESTRUCTURA DE PODER RURAL EN LA SOCIEDAD ESPAÑOLA DE LA RESTAURACIÓN, 1874-1902 *
}

\author{
ALICIA YANINI
}

Este artículo se centra en el análisis del control político en España y, en concreto, en la provincia de Valencia, en el último tercio del siglo XIX. Se utiliza el concepto «estructura de poder rural» contraponiéndolo al término más genérico de «funcionamiento del sistema político». El objeto que se persigue es subrayar la influencia política que tuvieron las provincias, hecho que no siempre se ha valorado en sus debidos términos. La primera parte es una reflexión acerca de cómo se ha estudiado el tema del caciquismo; la segunda analiza algunas de las características de la élite valenciana: ¿cuál fue su condición social y hasta dónde llegaba la capacidad de control e influencia política dentro del Estado de la Restauración alfonsina?

El caciquismo español de fines del XIX y principios del XX debe de analizarse a través de la peculiar configuración social de aquellos años. Los estudios electorales, por minuciosos que sean, no han sido hasta la fecha lo suficientemente amplios como para llegar a la comprensión del fenómeno social que conocemos con el nombre de caciquismo.

Sabemos que la estructura política, encaminada a evitar el golpe y fomentar el pacto del «encasillado», debe seguir siendo el objeto básico de investigación (1); asimismo, hay que prestar atención al funcionamiento de los partidos dinásticos y a la legislación electoral, que permitiría conocer la variedad de los métodos caciquiles utilizados según cual fuera la región en que se aplicarán dichas leyes. Es cierto que la estructura política del Estado se apoyaba en «comités caciquiles» 0 «tertulias de notables» (2), pero también lo es que carecemos de investigaciones empíricas que nos permitan conocer cuál era la extensión de sus respectivas influencias y las características que la misma revestía en las diferentes regiones españolas. Así pues, por poner un ejemplo, desconocemos el funcionamiento interno de los «comités locales

* Deseo agradecer el estímulo y los consejos del profesor José Varela Ortega. Sus comentarios han contribuido a mejorar el original de este artículo; no obstante, la responsabilidad por los resultados obtenidos es exclusivamente de la autora.

(1) TUSELL, J.: Oligarquia y caciquismo en Andalucia (Barcelona, 1976), pp. 23-121.

(2) TUÑÓN DE LARA, M.: Historia y realidad del poder (Madrid, 1975), p. 84. 
o provinciales" y poco sabemos de la concordia o disidencia que existiese entre el poder local, el de los notables provinciales, y el de quienes de hecho controlaban «la máquina»; en aquellos casos en que el poder no estuviese en unas mismas manos (3). En otras palabras, y siguiendo la terminología utilizada por el profesor Varela, se hace necesario confeccionar una «geografía de la influencia» (4); pues detrás de una aparente aceptación del «encasillado», que triunfa en la mayor parte de los distritos, no siempre encontramos una total desmovilización política y, en los «distritos rebeldes» que tuvieron una cierta movilización, encontramos explicaciones al porqué la sociedad rural aceptaba, o rechazaba, el encasillado». Es más, ello puede implicar unas relaciones notables-sociedad rural distintas según que las cosas sucedieran de un modo o de otro (5).

No cabe duda de que los estudios del caciquismo han prestado mayor atención al funcionamiento del sistema político que a la estructura de la propiedad y sus conexiones con el poder del mundo rural (6); pero no basta con analizar la «máquina electoral» montada por Romero Robledo en 1879 y apoyada en la administración pública de un Estado centralista, sino que se precisa un estudio del poder paralelo a dicho sistema político; matizando que quizá no sea correcto hablar de estructura de poder paralelo al del Estado durante el periodo de la Restauración. En 1879, La Revista de España, al conocer los propósitos de sinceridad electoral de Francisco Silvela, Ministro de Gobernación, lanzaba las siguientes preguntas:

(3) En el distrito de Segorbe, provincia de Castellón, tenemos un ejemplo. Los notables locales utilizaron sus influencias contra el "Cossi», o sea Victorio Fabra (a) «el tío pantorrilles", alcalde de Soneja y jefe de los «cossieros", que estaba apoyado en Madrid por el Duque de Tetuán. El «Cossi» impuso su candidato venciendo las influencias de los notables locales y de: Gobierno Silvela-Martínez Campos, que «encasilló» a Cirilo Amorós (C.A.): Cf. carta de Tomás Sebastián a C.A., 28-III-1879, (le comunica la proclamación de su candidatura por la Junta del "Comité de Segorbe»). De Carlos Lucía (presidente del «Comité») a C.A., 29-111-1879 (le explica que la provincia seguirá siendo turbulenta en manos de «las personas influyentes de Castellón» a la que los pueblos, temerosos, les entregan sus votos. De Juan Pérez Sanmillán a C.A., 8-IV-1879 (le habla de la "organización especial» que el Cossi, o sea Fabra, tiene..."). De Carlos Lucía a C.A., 11-IV-1879 («Esta noche recibo contestación a una que escribí a Sr. Silvela. Me dijo secamente que según noticias el candidato a quien apoyan los amigos del Gobierno es Cirilo Amorós»). De Carlos Lucía a C.A., 14-IV-1879, («El gobernador engaña al Gobierno»). De Vicente Ruiz Vila a C.A., 18-IV-1879 ( $T$ Te repito que la persona que hace años viene dirigiendo la política de la provincia es el Duque de Tetuán, y su verdadero y puede decirse exclusivo representante aquí es Fabra»). Todas estas cartas están en el Archivo de Cirilo Amorós (A.C.A.); agradezco a D. Vicente Genovés Amorós que me permitiera consultarlas.

(4) VARELA ORTEGA, J.: Los amigos politicos. Partidos, elecciones y caciquismo en la Restauración (1875-1900) (Madrid, 1977), p. 369.

(5) Ibid., pp. 359-363, muestra la utilidad de investigaciones que explican la «intensidad del vínculo que une al cacique con su clientela».

(6) Cfr. nota 18. 
«Cree de buena fe, que constituida la administración central, provincial y municipal como está, puede haber sinceridad electoral? ¿Pues no sabe que toda la administración es una máquina de guerra preparada y montada, durante cuatro años por el Gobierno anterior, en la espectación de unas elecciones?

El General Martínez Campos tendrá muy buenos deseos (...) los tendrá Silvela; de ellos participará todo el Gobierno: pero ¿y los gobernadores, y las comisiones provinciales, y los ayuntamientos, y los alcaldes?» (7).

Es claro que el caciquismo no lo inventó Cánovas, sabemos que «el triunfo del régimen moderado supu[so] una progresiva utilización del caciquismo desde el centro (...). La transformación de aquel caciquismo tradicional (...) en otro gubernamental y administrativo, identificado con el sistema político que lo patrocina[ba] y hasta lo impo[nía]", se dio ya en la época de Isabel II (8); pero ¿qué forzó al cacique español a dejar de controlar parcelas de poder autónomo e integrarse en la «máquina»? Y, sobre todo, ¿cuáles fueron las causas de que esa «máquina» dejara de funcionar en un determinado momento histórico?, al igual que antes dejó de ser efectivo el poder de caciques rurales no integrados. Las respuestas están en la configuración de aquella sociedad. De ahí que queramos subrayar el carácter social, junto al político-administrativo, del caciquismo. Asi pues, para profundizar en el tema, es necesario investigar las condiciones humanas en que se desenvolvía la vida rural (9), la estructura de la propiedad (10), el bandidismo (11), las variedades de cuerpos de seguridad existentes (12), la centralización del Estado (13), los tipos de

(7) La Revista de España (III-IV-1879) 133

(8) DE CASTRO, C.: La Revolución liberal y los municipios españoles (Madrid, 1979), pp. 132-133. Cf. también Varela Ortega, op. cit., pp. 401-404.

(9) DURÁN, J. A.: Historia de caciques, bandos e ideologías en la Galicia no urbana (Madrid, 1972) pp. 71-154.

(10) LYTTELTON, N. A. O.: «El patronazgo en la Italia de Giolitti (1892-1924), Revista de Occidente, 127 (1973) 96-97. Explica que el patronazgo tradicional tuvo mayor duración en regiones de contrato de «mezzadria».

(11) Ibid., pp. 106-107.

(12) LOPEZ GARRIDO, D.: La Guardia Civil y los origenes del Estado centralista (Barcelona, 1982), p. 162. Las aspiraciones de la burguesía agraria catalana se diferenciaban de la valenciana, cf. Yanini, A.: «Els cacics rurals valencians i la seva oposició a la guardia civil com a guarderia rural (1876-86)", Estudis d'História Agrària, 5 (1985) 132.

(13) LÓPEZ GARRIDO, op. cit. pp. 134-135. En otras palabras, se trata de analizar las causas y consecuencias del "centralismo ineficaz" de que nos habla Henner Hess, Mafia y crimen represivo (Madrid, 1976), pp. 221-227. 
asociación ciudadana que por entonces se practicaban (14) y, en definitiva, las causas profundas que favorecian una escasa participación en los hechos políticos y sociales (15).

Todo esto influyó en el modo en que los individuos canalizaron sus peticiones al Estado a través de instituciones públicas y privadas. Ambas estaban en manos de quienes ocupaban una posición de poder, a los cuales llamamos caciques en la medida en que privatizaban el ejercicio de las instituciones y controlaban las estructuras políticas. Lo podemos observar en las Cámaras legislativas del Estado, Diputaciones Provinciales, Ayuntamientos, Juntas de Riego, y asociaciones agrícolas, industriales y de comercio; los caciques las utilizaron para conseguir aquello que más les interesó e infringieron la ley sin excesivos temores a las sanciones legales. Así lo significaba el órgano de prensa de los silvelistas valencianos: «De subsistir este censo (...) quedaría ancho el campo al caciquismo (...). Nada tan sencillo entonces para el que tuviera un poco de influencia y dinero como reunir cinco mil individuos (...) y bajo el nombre de Cámara Agrícola Sociedad Económica, o cualquier otro análogo, llegar a las Cortes». (16).

Ya sabemos que uno de los rasgos más característicos del cacique era su actuación ilegal a favor de sus amigos y en contra de sus enemigos políticos, sirviéndose para ello de la Administración pública del Estado, la ocultación judicial, y la complicidad de políticos y funcionarios. Tanto los testimo-

(14) En este sentido, interesa estudiar las transformaciones que experimentó el asociamiento burgués: Cf. M. AGULHON, Le cercle dans la France Bourgeoise, 1810-1914, étude d'une mutation de sociabilité (París, 1977). Asimismo, se hace imprescindible el estudio de la influencia que las logias masónicas ejercieron sobre la política: Cf. M. C. RADICH, «Formas de organização política: sociedades patrióticas e clubes políticos, 1820-1836», O liberalismo na peninsula ibérica na primera metade do século XIX (Lisboa, 1981), pp. 120-122 y 139. También las logias valencianas se sirvieron del asociamiento masónico para conseguir objetivos políticos y fomentar la proliferación de casinos republicanos que combatieran el caciquismo de los partidos dinásticos. Así lo he constatado en un estudio realizado con C. Mellado y C. Ponce: «Republicanismo y masonería en la Valencia de la Restauración alfonsina, 1874-1902», en: Ferrer Benimeli (coord.): La masonería en la España del siglo XIX, II Symposium de metodología aplicada a la Historia de la masonería española. Salamanca 2-5 de julio de 1985. Ed. Consejería de Educación y Cultura (Junta de Castilla León, 1986).

(15) FUSI, J. P.: «El movimiento obrero en España, 1876-1914», Revista de Occidente, 131 (1974), pp. 209 y ss. El estudio del asociamiento obrero también es aclaratorio, pues la falta de cauces legales para la protesta social favoreció la desmovilización política y los motines violentos de los campesinos, acrecentando el excepticismo en la actividad parlamentaria. Este retraimiento, en definitiva, favorecía el caciquismo.

(16) «El Censo Electoral de la Cámara de Comercio», Las Provincias (20-I-1891). Cf. también A. Yanini, El caciquisme (Valencia, 1984) pp. $27-28$ (los conservadores valencianos controlaban los gremios contra los liberales que tenían el dominio de la Diputación provincial). Cf. asimismo «El cacics rurals..., op. cit. pp. 118-119 (la Liga de arroceros, el Gobernador y las Juntas de Riego, se vieron involucrados en métodos caciquiles consistentes en multas indebidas por plantaciones fuera del coto). 
nios de la época como los estudios históricos más recientes han coincidido en resaltar este punto, pero no olvidemos que éste es tan sólo un rasgo de un boceto más complicado que queda por acabar. Todavía quedan muchos puntos oscuros, de ahí que las afirmaciones hechas no sean siempre uniformes ni coincidentes; aunque sí son compatibles en muchos aspectos.

Dos son los puntos en que ya podemos anotar algunas discrepancias. Uno de ellos gira en torno al modo en que estaban organizadas las estructuras socio-políticas de la Restauración y el lugar que ocupaba en ellas la figura del cacique (17); el otro se refiere a las características del cacique, a sus vinculaciones con la Administración pública del Estado y con los intereses económicos de la zona en que desempeñaba su cacicato; la mayor parte de los historiadores del caciquismo han aceptado que «los caciques [eran] líderes de partidos que detentaban, más que la propiedad territorial, el poder administrativo» (18). Ahora bien, José Varela Ortega ha introducido una matización relevante: cuando el caciquismo es tradicional -apoyado en la deferencia- la Administración pública del Estado adopta un papel pasivo. Cosa que no sucede en los demás tipos de caciquismo, en que los vínculos entre el cacique y su clientela son diferentes. En cualquier caso, aunque el pasar de un caciquismo tradicional a otro gubernamental puede llevar aparejado algún cambio, no obstante - según el profesor Varela - ambos caciquismos siguen teniendo un denominador común: el control de la Administración (19).

Habría, pues, que analizar las razones que permitían que unos tuvieran el control sobre la Administración y otros no pudieran conseguirlo ni, en muchos casos, plantearse dicho objetivo. Así, por ejemplo, mientras la razón y la fuerza de un cacique tradicional podía estar en la propiedad de la tierra o en la herencia patrimonial de un prestigio familiar (20), esas mismas razones serían poco útiles para explicar el caciquismo no tradicional, no basado

(17) RICHARD, B.: «Etudes sur les Gouverneurs civils en Espagne de la Restauration à la Dictadure (1874-1923). Origine geographique, fonctions d'origine et évolution d'un personnel politico-administratif», Melanges de la Case de Valázquez, VIII (1972) 461-462; Chastagneret, G. Temime, E.: "Contribution à l'étude des sources et des formes de pouvoirs locaux dans l'Espagne rural contemporaine. Reflexion sur le caciquisme», Cahiers de la Mediterranée (Actes des Journées d'Etudes Bendor, 26-27 al 28 d'abril, 1978), p. 148.

(18) ÁLVAREZ JUNCO, J.: «Maneras de hacer historia, los antecedentes de la semana trágica», Zona abierta, 31 (1984) 49.

(19) VARELA ORTEGA, J.: «Los amigos políticos, funcionamiento del sistema caciquista", Revista de Occidente, 127 (1973) 64; cf. también la nota 8.

(20) THOMPSON, E. P.: «El entramado hereditario: un comentario», en: Tradición, revuelta y conciencia de clase. Estudios sobre la crisis de la sociedad preindustrial, (Barcelona, 1979) pp. 170-172. Sugiere el interés de estudiar el mantenimiento de los privilegios -aqui el caciquismo- en la costumbre de la herencia. 
en la deferencia y, por lo tanto, quizá el control de la administración fuera, en dicho caso, el elemento indispensable de poder. Esto último fue lo más usual durante la Restauración (21), aunque deberíamos profundizar en ello pues en Italia se dieron casos abundantes de caciquismo tradicional hasta los años de la Primera Guerra Mundial (22). Todo esto sería de gran interés para el caso valenciano, en que abundan los contratos de arrendamiento estable similares a los «mezzadria» italianos. Quizá eso explicaría, en parte, un tipo de caciquismo diferenciado del de Castilla, Andalucía o Extremadura (23); pues los arrendamientos estables permitían una cierta independencia económica que podía favorecer la deferencia y evitar violencias políticas. No obstante, como afirma O'Gorman, no basta con el análisis de la estructura de la propiedad, sino que también hay que prestar atención a la percepción que los contemporáneos tenían de la deferencia y la realidad patriarcal de la política electoral (24).

En mi opinión, tal y como he observado en la provincia de Valencia, todos los temas que se han ido anotando en esta primera parte del artículo deben ser integrados e interrelacionados entre sí. De ese modo, veremos que las discrepancias nunca pueden ser totales sino sólo parciales; pues la figura del cacique puede tener un significado ambivalente, según la zona en que domine, y según cuál sea la extensión geográfica de su influencia. Por lo tanto, hablaré del cacique valenciano de la Restauración evitando utilizar el término en un sentido unívoco y abstracto.

El cacique valenciano ejercía su poder en una comarca o localidad concreta, aunque su actividad le permitiera llegar hasta los centros de decisión del Estado. La fuente de su poder no era sólo político-administrativa, sino que también podía serlo la riqueza que poseía: en unos casos era la propiedad de la tierra; en otros, sus inversiones en negocios de comercialización de productos agrarios. Y, en ocasiones, la influencia política, el control de los canales de comercialización, y la propiedad de la tierra se concentraron en unas

(21) VARELA ORTEGA, op. cit., pp. 368-369.

(22) LYTTELTON, op. cit., p. 97. En Cataluña el contrato de «rabassa morta» favoreció una relativa estabilidad social, tal y como ha puesto de manifiesto E. C. Hansen, "The State and Land Tenure Conflicts in Rural Catalonian, Anthropological Quarterly (1969), p. 223.

(23) BALCELLS, A.: El problema agrario en Cataluña. La cuestión rabassaire, 1890-1936 (Madrid, 1980) pp. 51-55, 65-66, 78-80. La pérdida de la estabilidad de los aparceros llevó a luchas sociales encabezadas por líderes políticos dispuestos a cambiar el comportamiento electoral de los «rabassaires" y «masovers».

(24) O'GORMAN, F.: «Electoral Deference in "Unreformed" England: 1760-1832», The Journal of Modern History, 3 (1984) pp. 391-399. 
mismas familias (25). Ahora bien, no todos los propietarios se interesaron activamente por la política, ni por controlar personalmente la administración municipal. Aquí cabe preguntarse por qué unos propietarios desempeñaron dicho papel, mientras que otros - a veces los más grandes- no lo hicieron. En otras palabras, una de las fuentes de poder de los caciques fue la riqueza, pero no la única. Es más, durante la Restauración, solamente si estaban interesados en privatizar las instituciones públicas y en desempeñar un papel activo en política, podemos hablar de caciques en strictu sensu. Estos canalizaron las influencias políticas de las localidades a través del control del aparato administrativo y judicial (26). Asi pues, una vez conocidos los rasgos comunes de los diferentes caciques valencianos, habrá que investigar los rasgos diferenciales. Sólo así podremos establecer los diferentes comportamientos políticos.

Es improbable que la actitud política de un alcalde municipal, cuya única fuente de poder es el control de la Administración, sea igual a la de un terrateniente, o la de un bandido cuyo control político sobre la comarca se basa en la violencia (27). Encontramos ejemplos de bandidos, propietarios pequeños, grandes terratenientes, empleados de la Administración, etcétera; pero en todos los ejemplos surge el mismo interrogante: si ellos eran realmente los caciques o si, por el contrario, eran testaferros de terratenientes absentistas que los utilizaban como hombres de paja a su servicio (28). En cualquier caso, desempeñaban el papel de intermediarios entre la comunidad rural y las instituciones que personalizaban el poder del Estado. Era la estructura de dicho poder y el atraso social, con la mentalidad y actitudes políticas que ello comporta, lo que hacía factible la figura de estos intermediarios - o caciquesque a continuación intentaremos delimitar.

(25) Así lo he constatado en los distritos electorales de Sueca y Gandia: Exportación valenciana (17 y 24-I-1898), en el Fondo Documental de Navarro Cabanes, de la Hemeroteca Municipal de Valencia. Blay Navarro, J.: Documentos y datos para la Historia de la Ciudad de Oliva (Valencia, 1960) p. 584. «Necrologías» del Almanaque de las Provincias (A.L.P.) (1880-1903). «Actas de Diputados» del Diario de Sesiones del Congreso de los Diputados (1876-1901). Novell, N.: "De la Restauración a la monarquía parlamentaria», en El Llibre de la Safor (Gandía, 1983) p. 228. Además, se puede constatar en numerosas referencias de la prensa periódica valenciana, que critica a los caciques locales: «El feudo del Señor Sapiña», El Pueblo (13-IV1901). "De nuestro corresponsal en Oliva», El Mercantil Valenciano (6-VIII-1881).

(26) Cf. nota 21.

(27) El bandidismo valenciano estaba protegido por los caciques. Su independencia del poder, al igual que les sucedía a los caciques rurales tradicionales, era cada vez menor. Cf. texto del Diario de Sesiones del Congreso de los Diputados (26 noviembre 1901), publicado en A. Yanini: El caciquisme, op. cit., p. 25. El bandidismo, al igual que el caciquismo rural, tendió a declinar frente al poder del Estado. Es algo similar a lo descrito por Leonardo Sciascia para la «mafia rural». Cf. "Mafia, mafler, maflu, mohaft...», en: La Sicile comme metaphore, Editions Stock, 1979, p. 54. 
Para situar, en sus debidos límites, la figura del cacique valenciano, he investigado la condición social y la localización geográfica. Esta última queda fijada de acuerdo con el ámbito en que se extendiera su actividad política, pues aunque solía comenzar en un pueblo o comarca, podía rebasar sus primeros límites y extenderse por toda la provincia, incluso llegar hasta el Congreso o el Senado; de ahí que senadores y diputados fueran tachados de caciques en los textos de la época (29), pues de hecho, y no sólo por similitud en su comportamiento, lo eran. Para analizar la condición social he prestado atención a los medios de vida y la profesión. De acuerdo con estos dos aspectos biográficos (30), y teniendo en cuenta que mis afirmaciones van dirigidas a los caciques valencianos de la Restauración, se puede observar que tal apelativo se aplicó indistintamente a quienes desempeñaban profesiones liberales y a quienes detentaban la tierra, los negocios comerciales o las fi-

(28) DISTRITO ELECTORAL DE SUECA (Provincia de Valencia)

\begin{tabular}{|lll|}
\hline Manuel Sapiña & Cullera & $\begin{array}{l}\text { Propietario de una de las principales fincas de } \\
\text { naranjos. } \\
\text { Diputado Provincial y a Cortes. } \\
\text { Vicente Diego }\end{array}$ Cullera \\
Cristóbal Gómez Ruiz & $\begin{array}{l}\text { Protario de una de las principales fincas de } \\
\text { naranjos. } \\
\text { Empleado de la Administración uSapiñista y } \\
\text { Dieguista". }\end{array}$ \\
\hline
\end{tabular}

Cf. nota 25 y El Mercantil Valenciano (1-IV-1886). Ejemplos similares se ha podido constatar en los distritos electorales de Albaida, Gandía y Chelva.

(29) Los notables provinciales, que ocuparon los cargos de senadores y diputados a Cortes, eran tildados de caciques: «Damos la bienvenida al Sr. Romero Leal... nada tendrá que hacer con los ilegales, o sea la gran mayoría de los habitantes de esta provincia; pero vaya estudiando el tratado del Príncipe de Maquiavelo para entenderse con las tres o cuatro docenas de conservadores que aquí se disputan a palo limpio el cetro del caciquen. El Mercantil Valenciano (18 marzo 1879).

(30) Los datos biográficos proceden de las siguientes fuentes: (A.L.P.), 1880-1903; Añón Marco, V.: Hijos ilustres del Reino de Valencia (notas biográficas) (Valencia, 1973); Azorín, El Parlamentarismo Español (Barcelona, 1968); Cuco Giner, A.: Aspectes de la politica valenciana del segle XIX (Barcelona, 1963); del mismo autor, Republicans y camperols revoltats (Valencia, 1975); Gascón Pelegrí, V.: Prohombres valencianos de los últimos cien años (Valencia, 1978); Janini Janini, R.: Principales impulsores y defensores de la riqueza agrícola valenciana en la segunda mitad del siglo XIX (Valencia, 1923); Momblanch, F. de P.: Cien abogados ilustres del Colegio de Valencia (Valencia, 1961); Llorente Falco, T.: De mi Valencia de otros tiempos, memorias de un sesentón (Valencia, 1942-47); «Valencianos sobresalientes», en Las Provincias, recortes de prensa del fondo documental Serrano Morales, Biblioteca del Ayuntamiento Municipal de Valencia; Pérez Ruiz, P. M.: Glorias Valencianas (Valencia, 1955); Sanchís Guarner, M.: Renaixença al País Valencià (Valencia, 1982); Tebar, E. de: Las Segundas Cortes de la Restauración. Semblanzas parlamentarias (Madrid, 1879-1880); Sánchez Ortiz, M.: Las Primeras Cámaras de la Regencia (Madrid, 1886); Sánchez de los Santos, M.: Las Cortes Españolas de 1910. Cf. también la nota 25 . 
nanzas. Quizá en Valencia no siempre podamos hablar del «cacique» que controla un territorio concreto. En algunos casos puede ser así, pero en otros casos existían unas influencias politicas, las cuales permitían que se vieran urepresentados», más que «subyugados»; es decir, que en Valencia, en muchos casos, el cacique era simplemente el portavoz de un grupo de notables de la comarca (31).

Ejemplos de lo afirmado se pueden encontrar en la provincia de Valencia y uno de ellos merece ser contado con detalle: sucedió en el distrito electoral de Chelva entre 1876 y 1901 . A lo largo de estos 25 años se realizaron en España un total de 11 elecciones legislativas y el cacique del distrito de Chelva tan sólo fue derrotado en dos ocasiones. Es más, esto no fue así porque el Ministerio de Gobernación cediera el distrito voluntariamente tras el pacto del encasillado, sino porque, al contrario, gobiernos sucesivos recurrieron a métodos fraudulentos para combatir a los caciques locales pero no lograron vencerlos. El Gobierno utilizó la Administración y los cuerpos de seguridad del Estado para derrotar al candidato del distrito de Chelva. Con tal fin, destituyó a guardas rurales, administradores de correos, administradores de rentas, alcaldes y un largo etcétera; pero ni aún así logró doblegar a los caciques rurales que se mantenían fieles al cacicato de Gil Roger y Duval (32), que había colocado a sus familiares y amigos en los diferentes cargos que le suministraba la Administración de un Estado como el de la Restauración, centralizado pero con grandes insuficiencias e ineficacia manifiesta (33). E amiguismo, familismo y patronazgo formaban los cimientos de este poder paralelo al del Estado.

Tras sucesivos enfrentamientos entre el poder gubernamental y el caciquismo local, el distrito de Chelva logró «hacerse» un «diputado natural» que no se sometió al «Turno». Veamos cuáles eran las características de «el Diputado»: su nombre era José Manteca Oria y su profesión era la abogacía. Pertenecía al partido liberal y trabajaba en Madrid, allí conoció a Gil Roger y Duval -cacique de Chelva y senador electo por la provincia (34) - que le ani-

(31) Cf. nota 3. El distrito electoral de ALBAIDA es un ejemplo principal: demuestra que la asociación de notables locales y provinciales combatió a caciques locales aislados. El Mercantil Valenciano (20-II-1886); «Las elecciones en el distrito de Albaida», en Las Provincias (25I-1891) y (17, 19-I-1891); "Manifiesto electoral de D. Enrique Dupuy de Lome, candidato por el distrito de Albaida», en Las Provincias (13-I-1891).

(32) El Mercantil Valenciano (20-1-1876).

(33) HERR, Richard: «Spainm, en: Spring, D. (ed.) European Landed Elites in the nineteenth Century, The John Hopkins University Press, pp. 113-114.

(34) Los datos biográficos de la familia Roger proceden de: Azorín, op. cit., pp. 194-197; «Representantes de Valencia en las Cortes», año 1881 (A.L.P.), p. 198. Relación de senadores aparecida en A.L.P., años 1883, 1885, 1888, 1889, 1890, 1891. «Necrologías", año 1941 (A.L.P.) p. 325 . 
mó a solicitar la plaza de juez municipal en el mencionado distrito. Una vez allí, se casó con la hija de Gil Roger y, más tarde, la familia le confió la representación política en el Congreso de los Diputados y se convirtió en el «Diputado natural» del distrito (35).

Así pues, tal y como ya afirmó en su día Romero Maura (36), los diputados no siempre eran agentes de Madrid y los caciques, apoyados por su clientela, podían enfrentarse y vencer en el pacto del encasillado. Pero vayamos un poco más adelante en el razonamiento y profundicemos en los entresijos del ejemplo que hemos elegido. Para conseguir tal objetivo es necesario conocer algunos datos biográficos de Gil Roger y Duval: era un liberal que había nacido en Chelva y pertenecía a una familia modesta. Se enriqueció con el tráfico de arriería y el comercio, a partir del cual creó una vasta fortuna, asociándose para ello con un personaje apellidado Santaella (37); aunque desconozco los datos biográficos de este socio de Gil Roger, he podido averiguar que Santaella era de Cuenca, provincia en la que Gil Roger pagaba tal cantidad de contribución al Estado que ocupaba el $4 .^{\circ}$ lugar en la lista de los 50 mayores contribuyentes de la provincia (38).

En resumidas cuentas, el poderío de Gil Roger no sólo es un hecho demostrado por las narraciones biográficas consultadas, sino por los datos estadísticos de la Hacienda Pública española. Si a todo esto añadimos que tenía gran amistad con los principales miembros de la élite política, como Sagasta o Ruiz Zorrilla, y que él mismo había desempeñado el cargo de senador y diputado a Cortes, no cabe ya la menor duda de que Gil Roger (39), cacique y senador durante la Restauración, además de rico propietario y comerciante, formaba parte de la "oligarquía» de la que nos habla Joaquín Costa (40).

El ejemplo que hemos entresacado nos lleva a observar que la localización geográfica no era tan local como decía Joaquín Costa; pues el poder de muchos caciques iba más allá del mero control de la Administración pública del municipio. Así, Gil Roger, entre otros, actuaba de empresario de sus propias tierras, finanzas o negocios comerciales, y empleaba asimismo su influencia política en Madrid y en la provincia. Es más, en el ejemplo que he-

(35) «Necrologías», año 1902 (A.L.P.) p. 479.

(36) ROMERO MAURA, J.: «Apéndice a la sección 2», en: R. Carr: España 1808-1939 (Barcelona, 1970) pp. 471-472.

(37) Cf. nota 34.

(38) CONGOST, Rosa: «Lista de los mayores contribuyentes de 1875", Agricultura y Sociedad, 27 (abril-junio-1983), p. 346. Gil Roger ocupaba el 4. ${ }^{\circ}$ lugar con 4.310,08 pesetas.

(39) Cf. nota 34.

(40) COSTA, J.: Oligarquia y Caciquismo como la forma actual de Gobierno en España. Información en el Ateneo de Madrid, 1901 (Madrid, 1975), pp. 3-98. 
mos seguido, observamos que utilizaba a profesionales para que desempeñaran cargos políticos. En otras palabras, el cacique real era Gil Roger, que delegaba una parte de su poder en manos de los diputados, caciques lugareños, burócratas y empleados de la Administración, mientras él desempeñaba en Madrid el cargo de senador (41). Pero, en definitiva, la red de clientela local, apoyada en el familismo y el patronazgo, giraba en torno a Gil Roger y no en torno a quienes controlaban la Administración pública del municipio y ocupaban puestos de responsabilidad política: alcaldes, diputados provinciales, a Cortes, etcétera. En otras palabras, el cacique real de un pueblo, comarca, distrito o provincia, era aquel que tenía en torno a síla red de clientela que le permitía presionar frente a otros e intentar imponer sus condiciones. Fijar la atención en el alcalde, el maestro, o el cura del pueblo es desenfocar el problema (42); o, si se quiere, es dirigir el objetivo a una parte minúscula de lo que se quiere investigar. Eso nos permite conocer las características de un cacique rural con mayor detalle y minuciosidad, pero a veces raya en lo anecdótico y dificulta la comprensión del sistema político de la Restauración Alfonsina (43).

Para evitarlo es necesario reconocer que Joaquín Costa nos legó una visión esquemática del modo en que estaban organizadas las estructuras sociopolíticas: diferenciaba entre prohombres, que configuraban la oligarquia estatal, y caciques, cuyo poder se extendía tan sólo en el estrecho marco de una localidad o una región; o sea, diseñaba una pirámide de poder en la que los oligarcas quedaban por encima de los caciques y pactaban con estos últimos desde una posición de fuerza, apoyándose en la autoridad de un Gobierno central que, asimismo, se servía del gobernador, los alcaldes, y otras autoridades de la provincia para quedar legitimado, a través de un fraudulen-

(41) Siempre fue elegido senador «por la provincia», no por derecho propio ni por las corporaciones. A lo largo de 10 años (1880-1890) el número y nombre de los senadores valencianos se mantiene casi sin variación. Había un total de 9 senadores por año. De dicho número, 3 eran fijos por ser vitalicios y en los otros 6 , aunque eran elegibles, apenas se dan cambios, siempre se alternan los mismos nombres. En resumen, a lo largo de 10 años no aparecen 90 nombres distintos de senadores, sino que dicho cargo se lo reparten entre 27 personas. Esto nos da una idea bastante precisa de la relevancia política de Gil Roger y Duval, senador en 1882-1884-1887-1888-1889-1890. Cf. nota 34.

(42) Con tal afirmación no niego el interés de obras como la de Barnett Singer, Villages Notables in nineteenth-Century France, Priest, Mayors, Schoolmasters, (New York, 1983). Muy al contrario, un estudio como éste nos permitiría conocer las causas del republicanismo y el anticlericalismo, unidos en algunos distritos rurales valencianos. Asimismo, entenderíamos que algunas logias masónicas valencianas defendieran candidatos declaradamente masónicos y enemigos de la Iglesia Católica. Cf. nota 14.

(43) Cf. nota 8. El estudio de la comunidad rural sin ver sus conexiones con el Estado puede dificultar la comprensión. De igual modo que estudiar a personajes locales sin ver quiénes eran sus superiores provinciales puede llevarnos también a una estrechez de miras. 
to sistema electoral que lo envolvía todo en una falsa apariencia democrática (44).

Muchos estudiosos del caciquismo han aceptado el esquema "costista» para el análisis del poder socio-político (45). Sin embargo, a partir del estudio realizado en la provincia de Valencia, este esquema "costista" para la comprensión del funcionamiento político de la Restauración debería ser puesto en entredicho, tal y como ya han hecho algunos autores (46). Por una parte, es cierto que los caciques se definen siempre en base a su poder local, pero no es menos cierto que en la provincia de Valencia durante la Restauración había muchos «caciques por delegación»: la aristocracia terrateniente y la financiera acostumbraba hacer una delegación de poder en manos de administradores, políticos locales, profesionales, etcétera. En estos casos existía una separación clara entre oligarcas y caciques, pero estos últimos no hacian más que ejecutar las órdenes de los primeros. Por otra parte, son muchos los casos en que el poder oligárquico y el caciquil estaban en unas mismas manos, y así lo hemos anotado anteriormente al hablar de Gil Roger, "caciquesenador» del distrito de Chelva.

Vemos mezclados los dos temas en que hemos observado discrepancias en la interpretación del caciquismo: la localización geográfica, que no siempre era tan local, la condición social del que ejerce de cacique, la cual no siempre estaba separada del que ejerce de oligarca, ni en todos los casos estaba tan sólo circunscrita al estrecho marco de la Administración y el poder que de ella se deriva. En definitiva, en muchos casos la oligarquía valenciana se confundía con el cacique local y provincial que conservaba para sí una representación política que no podía ser cuestionada. El conflicto entre la estructura de poder de la comunidad rural, el de la aiputación provincial y el del Estado, estaba siempre latente, aunque sólo afloraba y llegaba a la opinión pública en los momentos de contienda electoral. De ahí que sean los períodos electorales los que pueden arrojar más luz sobre el tema.

\footnotetext{
(44) COSTA, J.: op. cit., pp. 19-27.

(45) HERR, R.: op. cit., pp. 115-117.

(46) Cf. nota 17.
} 